\title{
Odontoblast morphology and dental repair
}

\author{
P.E. Murray ${ }^{a, *, 1}$, I. About ${ }^{b}$, P.J. Lumleyc, J.-C. Franquin ${ }^{b}$, L.J. Windsor ${ }^{a}$, \\ A.J. Smith ${ }^{c}$
}

\author{
${ }^{a}$ Oral Biology, Indiana University School of Dentistry, 1121 West Michigan Street, Indianapolis, \\ IN 46202-5186, USA \\ ${ }^{\mathrm{b}}$ Faculte d'Odontologie, Université de la Mediteranée, Interface Matrice Extracellulaire Biomateriaux, \\ 27 Bvd Jean-Moulin, 13385 Marseille, Cedex 5, France \\ 'School of Dentistry, The University of Birmingham, St Chad's Queensway, Birmingham, \\ B4 6NN, UK
}

\section{KEYWORDS}

Tertiary dentinogenesis;

Cavity restoration; Pulp;

Odontoblast

\section{Introduction}

The repair and maintenance of tooth dentine is a well-established function of a single layer of odontoblast cells that secrete an extracellular matrix and regulate dentine mineralisation. Odontoblasts are highly differentiated post-mitotic cells that are capable of secreting primary, secondary and tertiary dentin matrix. ${ }^{1}$ With their peripheral location in the dental pulp and their cellular

\begin{abstract}
Summary Objectives. To investigate the changes in morphology and activity of pulp odontoblasts in response to cavity restoration variables and patient factors.

Methods. Class $V$ non exposed cavities were prepared in the intact 1st or 2nd premolar teeth of 27 patients, aged between 9 and 17 years-old. Following tooth extraction, the area of reactionary dentine and the area of the odontoblasts were measured using computerised histomorphometry.

Results. The cytoplasm to nucleus ratio of the odontoblasts was found to increase beneath cut dentinal tubules, following the secretion of reactionary dentine. However, none of the patient or preparation variables were found to be correlated with changes in the odontoblast cytoplasm to nucleus ratio.

Conclusions. Morphological changes in human odontoblasts is directly related to their capacity to repair dentine injuries and provide pulp protection. Changes in odontoblast morphology reflect secretory activity.
\end{abstract}


is secreted by newly differentiated odontoblast-like cells. ${ }^{7,8}$ The secretion of reactionary dentine is the main postoperative odontoblast repair response to the presence of a cavity carefully cut into the dentine of a tooth. The difficulty with measuring odontoblast responses to a cavity cut into dentine is that their reactions and secretory behaviour are the end result of the effect of the caries lesion, and all the cavity preparation and restoration events. The odontoblast responses to each of these events can be hard to separate but among the factors involved are the method of cavity preparation, ${ }^{9}$ condition of the dentine cavity wall, ${ }^{10}$ presence of bacteria, ${ }^{11}$ application method of the restoration material, ${ }^{12,13}$ and pulpal inflammation. ${ }^{14}$ The relative importance of these multiple events probably varies from one cavity restoration to another and this may explain why there has been great difficulty in trying to correlate the morphology of odontoblasts with their tertiary dentinogenic secretory behaviour. ${ }^{2}$ Nevertheless, the successful resolution of restorative treatments is dependent upon harnessing and utilising the natural dentine repair responses of the odontoblasts. ${ }^{15}$ There is no artificial material that can be placed into a tooth that provides better protection for the pulp than dentine. ${ }^{16}$ Although the numbers of odontoblasts have been found to be critical to accomplish dental repair, ${ }^{17}$ information about the effect of odontoblast morphology is limited. Hence despite the complexity of odontoblast reactions, responses, and activities, there is a clear need to investigate the precise nature of the control of dentinogenesis. For these reasons, the purpose of this work was to investigate the quantitative relationship between changes in odontoblast morphology and reactionary dentine secretory activity, and to examine the effects of patient factors and cavity restoration variables.

\section{Materials and methods}

Twenty-seven patients aged between 9 and 17 years of age, had class $V$ preparations into intact first or second premolars that were scheduled for

Table 1 Pathohistometric information from 27 patients.

\begin{tabular}{|c|c|c|c|c|c|c|c|c|c|c|}
\hline A & B & $C$ & D & $E$ & $\mathrm{~F}$ & G & $\mathrm{H}$ & I & $\mathrm{J}$ & $\mathrm{K}$ \\
\hline 3.977 & 2.528 & 17 & 39 & 2.788 & $(++)$ & Dycal & $\mathrm{F}$ & Md & 0.627 & 2.318 \\
\hline 3.753 & 2.616 & 11 & 28 & 0.472 & $(++)$ & Dycal & $M$ & $M x$ & 1.056 & 1.233 \\
\hline 3.106 & 2.753 & 14 & 28 & 0.945 & $(+)$ & Dycal & $M$ & $M x$ & 0.878 & 1.800 \\
\hline 4.754 & 2.673 & 14 & 32 & 0.977 & $(++)$ & Dycal & $M$ & $M x$ & 0.294 & 0.294 \\
\hline 5.293 & 2.926 & 17 & 35 & 0.740 & $(+)$ & Dycal & $M$ & Md & 0.841 & 0.335 \\
\hline 4.554 & 2.866 & 11 & 33 & 0.331 & $(+)$ & Dycal & $M$ & Md & 1.381 & 1.513 \\
\hline 2.488 & 2.255 & 11 & 33 & 0.000 & $(+)$ & Dycal & $M$ & Md & 1.694 & 1.527 \\
\hline 3.784 & 2.776 & 14 & 57 & 1.575 & $(+)$ & Dycal & $F$ & $M x$ & 1.104 & 1.392 \\
\hline 3.885 & 3.043 & 14 & 56 & 1.827 & $(+)$ & Dycal & $M$ & $M x$ & 0.878 & 0.686 \\
\hline 3.918 & 3.110 & 9 & 150 & 0.472 & $(++)$ & Dycal & $F$ & Md & 1.381 & 0.372 \\
\hline 3.649 & 2.833 & 10 & 85 & 1.496 & $(+)$ & Dycal & $M$ & $M x$ & 1.129 & 1.412 \\
\hline 3.989 & 2.911 & 10 & 56 & 0.977 & $(+)$ & Dycal & $\mathrm{F}$ & $M x$ & 1.030 & 0.918 \\
\hline 2.787 & 2.520 & 11 & 74 & 0.000 & $(+)$ & Dycal & $\mathrm{F}$ & $\mathrm{Md}$ & 1.631 & 1.261 \\
\hline 2.638 & 2.735 & 11 & 163 & 0.000 & $(+)$ & Dycal & $M$ & $M x$ & 1.004 & 1.713 \\
\hline 4.000 & 3.032 & 10 & 124 & 0.787 & $(+)$ & Dycal & $M$ & $M x$ & 0.960 & 2.059 \\
\hline 3.638 & 3.084 & 11 & 84 & 0.536 & $(+)$ & Dycal & $F$ & $M x$ & 0.765 & 0.730 \\
\hline 2.716 & 2.578 & 10 & 28 & 0.000 & $(++)$ & IRM & $M$ & Md & 2.237 & 2.237 \\
\hline 4.381 & 2.842 & 12 & 77 & 1.272 & $(++)$ & IRM & $F$ & $M x$ & 0.567 & 1.544 \\
\hline 4.792 & 2.828 & 12 & 28 & 0.238 & $(++)$ & IRM & $F$ & Md & 1.600 & 0.159 \\
\hline 4.589 & 2.733 & 12 & 123 & 0.120 & $(++)$ & ZOE & $M$ & $M x$ & 1.224 & 2.105 \\
\hline 4.166 & 2.774 & 10 & 127 & 0.155 & $(++)$ & ZOE & $F$ & $M x$ & 1.565 & 1.651 \\
\hline 4.068 & 2.728 & 10 & 90 & 0.034 & $(+)$ & ZOE & $\mathrm{F}$ & Md & 1.615 & 1.408 \\
\hline 2.423 & 2.467 & 16 & 61 & 0.000 & $(++)$ & ZOE & $\mathrm{F}$ & $M x$ & 1.451 & 0.956 \\
\hline 2.616 & 2.551 & 10 & 29 & 0.000 & $(+)$ & ZOE & $\mathrm{F}$ & $M x$ & 0.947 & 1.663 \\
\hline 2.947 & 2.807 & 10 & 28 & 0.000 & $(+)$ & ZOE & $\mathrm{F}$ & Md & 0.947 & 2.732 \\
\hline 2.453 & 2.622 & 10 & 28 & 0.000 & $(++)$ & ZOE & $M$ & Md & 0.984 & 0.000 \\
\hline 3.221 & 2.444 & 10 & 154 & 0.353 & $(+++)$ & Dycal & $\mathrm{F}$ & Md & 0.782 & 1.619 \\
\hline
\end{tabular}

A, The mean cytoplasm to nucleus ratio of 25 odontoblasts beneath the cut dentinal tubules of cavity preparations; $B$, The mean cytoplasm to nucleus ratio of 25 odontoblasts opposite and independent of the cavity preparations; C, Age of patient (years); D, Time elapsed since surgery; $E$, Reactionary dentine area; $F$, Inflammation (+, slight, ++, moderate, +++, severe); G, Restoration material; H, Sex of patient (M, male, F, female); I, Tooth position (Md, mandibular, Mx, maxillary); J, Remaining dentine thickness; $\mathrm{K}$, Restoration volume. 
extraction, at the Dental Hospital of Marseille (Table 1). The Class V preparations were placed in the buccal surface, $1 \mathrm{~mm}$ above the level of the cemento-enamel junction. Preparations were cut using an intermittent application of the Airotor with water spray to remove the enamel followed by cutting with a Maillefer 129, ISO 010 bur using the least possible pressure at a drill speed of $4000 \mathrm{rpm}$ with water spray coolant. The preparations were cut into the dentine to a range of remaining dentine thickness (RDT) between 0.294 and $2.237 \mathrm{~mm}$, and axial floor widths with a mean of $2.27 \mathrm{~mm}$. These parameters were measured from histological sections. The floor of the preparations was maintained curved and parallel to the outer surface of the tooth. The walls of the preparations were immediately conditioned with a $17 \%$ Disodium ethylene diamine tetraacetate solution $\mathrm{pH} 8$ (Roth International, Chicago, USA), for $15 \mathrm{~s}$, flushed with sterile water for $5 \mathrm{~s}$, and dried with an extremely light airstream for $2 \mathrm{~s}$. Teeth were randomly assigned to three experimental groups for restoration (Table 1). Amalgam (Contour, Kerr, Italy) was used to restore 17 preparations, in conjunction with a calcium hydroxide lining material (Dycal, Dentsply Caulk, Milford, DE, USA). A further seven preparations were restored with zinc-oxide eugenol (ZOE) (Kalzinol, Dentsply Caulk, Milford, DE, USA) as well as a further three preparations with the Intermediate Restoration Material (IRM) (De Trey Dentsply, Zurich, Switzerland). All materials were prepared and used, strictly according to manufacturers' instructions. At the end of the post-operative interval, the extracted teeth were fixed in $10 \%$ neutral-buffered formalin for $24 \mathrm{~h}$, demineralised in a sodium formic acid solution $(3.4 \% \mathrm{HCOONa}$ in $15 \%$ Formic acid) for 21 days, and then routinely processed and embedded in paraffin wax for histological examination. Sections were cut at $6 \mu \mathrm{m}$ and routinely stained with haematoxylin and eosin. The pulpal inflammatory responses were categorised as slight, moderate or severe according to Federation Dentaire Internationale standards and criteria published previously. ${ }^{15,17,18}$ The area of reactionary dentine was estimated histomorphometrically at $\times 100$ magnification, using a grid eyepiece graticule. ${ }^{19}$ The cytoplasm to nucleus ratio ${ }^{20}$ was calculated by automated computer image analysis, by tracing the odontoblast nucleus and odontoblast cell cytoplasm membrane at $\times 670$ magnification (Seescan, Ltd, UK). Fifty odontoblasts that were cut longitudinally to the plane of tooth section were analysed in each tooth section. The raw data from all the experiments was examined using linear regression analysis of variance (LRANOVA) tests for data containing regression and analysis of variance (ANOVA). The statistical tests compared the difference between means (Statview, SAS Inc Cary, NC, USA) at a significance of $p \leq 0.05$. ANOVA post hoc tests ${ }^{21}$ were used to compare the differences between variables. These methods have been claimed to be the most versatile and most conservative multiple comparison statistical tests. ${ }^{22}$

\section{Results}

\section{Pathohistometric analysis}

Pathohistometric raw data collected from twenty-seven restored teeth. For each tooth, the cytoplasm to nucleus ratio, age of patient, time elapsed since surgery, reactionary dentine area, inflammation, restorative material, sex of patient, tooth position, RDT and cavity volume is shown in Table 1.

\section{Identification of reactionary dentine}

A histomorphological evaluation of the extracted premolar specimens, revealed the presence of a tertiary dentine matrix beneath dentinal tubules cut by preparations, showing tubular continuity between the secondary dentine matrix and the preexisting odontoblasts (Fig. 1). These observations were necessary to classify the secreted dentine matrix as being reactionary in origin. ${ }^{23}$

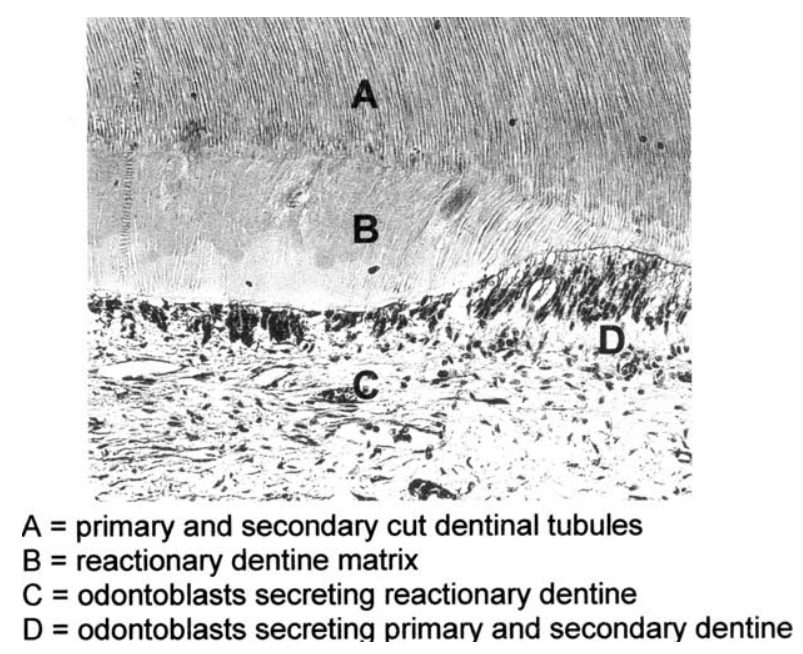

Figure 1 The histology of reactionary dentine beneath cut dentinal tubules. 


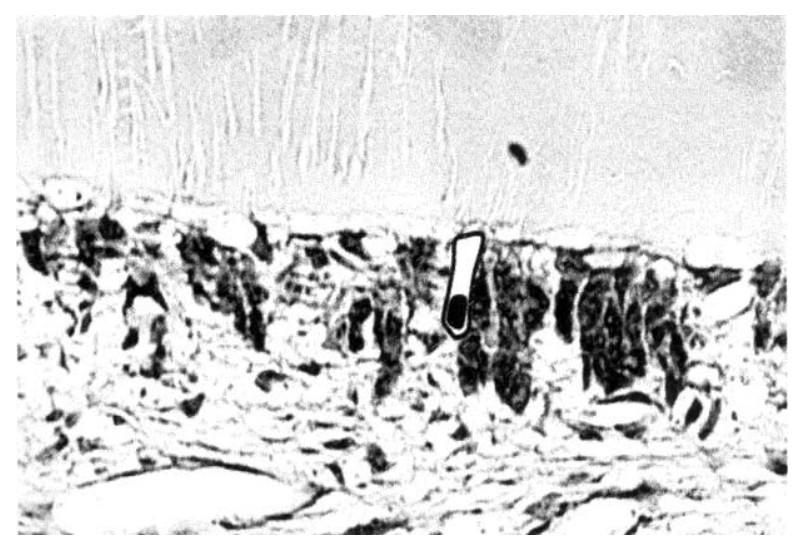

Figure 2 Odontoblast morphology associated with reactionary dentin matrix secretion.

\section{Odontoblast morphology}

Odontoblasts beneath cut dentinal tubules associated with reactionary dentine secretion were found to have an increased cytoplasm to nucleus ratio (Fig. 2), in comparison with odontoblasts independent of the cavity preparation ANOVA $p=0.0001$ (Table 2) (Fig. 3). The cytoplasm to nucleus ratio of odontoblasts beneath cut dentinal tubules associated with reactionary dentine, increased by approximately one third over less active odontoblasts (Fig. 4).

\section{Area of reactionary dentine secreted}

The area of reactionary dentine secreted beneath cut dentinal tubules were found to be related to the odontoblast cytoplasm to nucleus ratio (Table 2). The size of the odontoblast cytoplasm to nucleus ratio was greater in odontoblasts which had secreted larger areas of reactionary dentine, in

Table 2 Sequence of the correlation between the underlying odontoblast cytoplasm to nucleus ratio and cavity preparation and restoration factors.

\begin{tabular}{ll}
\hline Variable measured & $p$-Value \\
\hline $\begin{array}{l}\text { Mean odontoblast cytoplasm to nucleus ratio } \\
\text { independent of cut dentinal tubules }\end{array}$ & 0.0001 \\
Area of reactionary dentine secreted & \\
Time elapsed since surgery after 28 & 0.0003 \\
days & 0.0541 \\
Pulpal inflammatory reaction & \\
Gender of patient & 0.277 \\
Age of patient & 0.251 \\
Remaining dentine thickness & 0.324 \\
Restoration material & 0.493 \\
Premolar position & 0.542 \\
Restoration volume & 0.636 \\
\hline
\end{tabular}

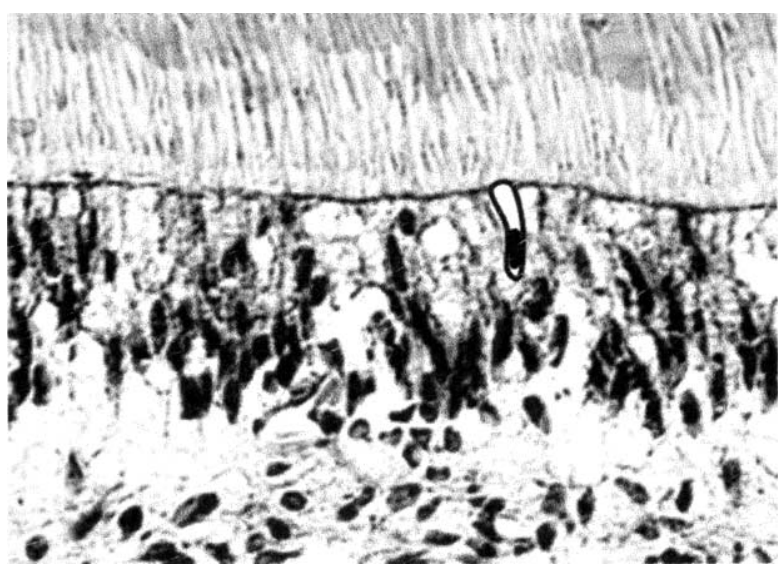

Figure 3 Odontoblast morphology independent of the site of cavity preparation, and with an absence of reactionary dentine matrix secretion.

comparison with odontoblasts which secreted small areas or no reactionary dentine matrix (Fig. 5).

\section{Time elapsed since surgery}

The odontoblast cytoplasm to nucleus ratio of odontoblasts involved in reactionary dentine secretion appeared to decrease slightly between 40 and 160 days since surgery (Fig. 6), although the sample size was too small to be statistically significant (Table 2). Reactionary dentine secretion were found to be almost fully formed at 28 days since surgery, this would suggest that after the secretion of reactionary dentine has terminated, the cytoplasm to nucleus ratio of odontoblasts decreases slightly over time, to resume their prereactionary dentine morphology (Fig. 6).

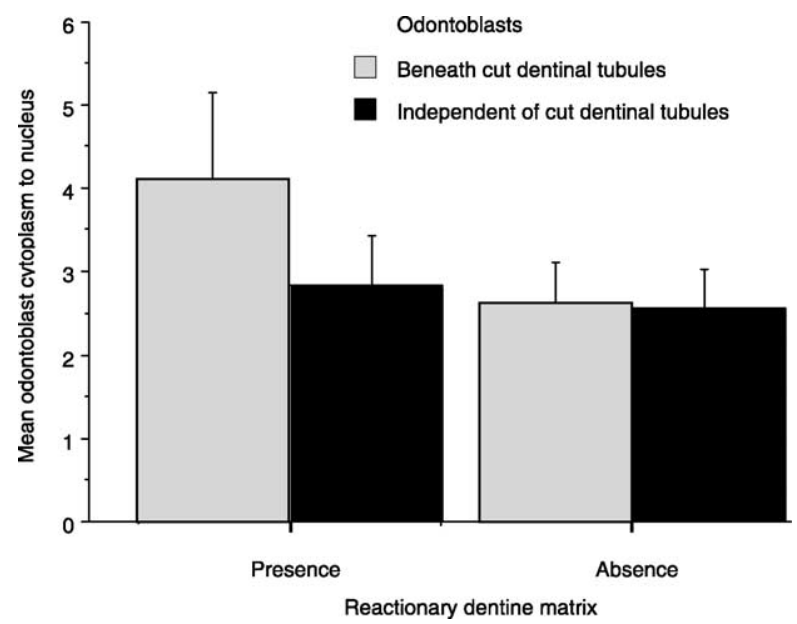

Figure 4 Reactionary dentine matrix secretion and odontoblast morphology. 


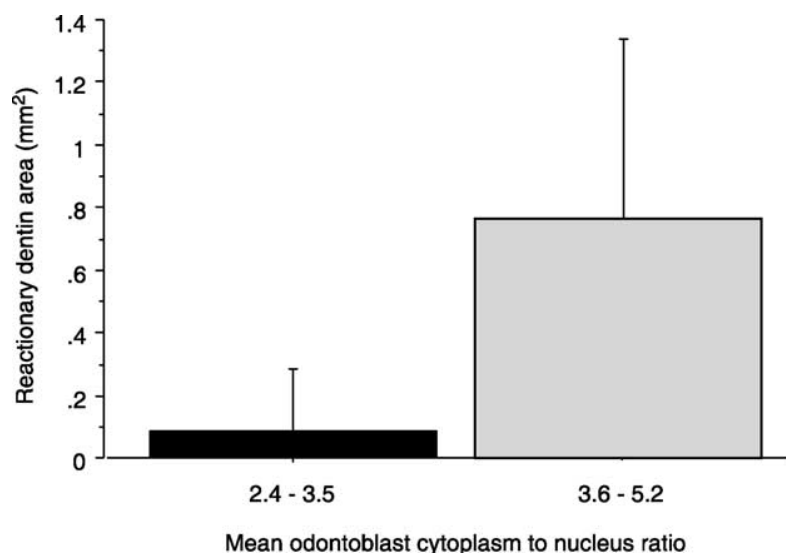

Figure 5 Reactionary dentine area and odontoblast morphology.

\section{Variables with an insignificant correlation to the reactionary dentine response}

The following variables were found to have an insignificant correlation with the cytoplasm to nucleus ratio of odontoblast cells; age of the patient; time elapsed since surgery; restoration variables such as the floor surface area, depth, volume, width, and RDT; pulpal inflammatory reaction; gender of patient; choice of Dycal, IRM or ZOE cavity restoration material and premolar tooth position (Table 2 ).

\section{Controls}

The RDT of all the cavity restorations was examined within each of the test groups to remove the possible influence of differences in RDT of the cavity preparations (Table 1). No statistical differences $p=0.05$ were observed for; age of the patient at treatment (ANOVA $p=0.661$ ); restoration material (ANOVA $p=0.519$ ); pulpal

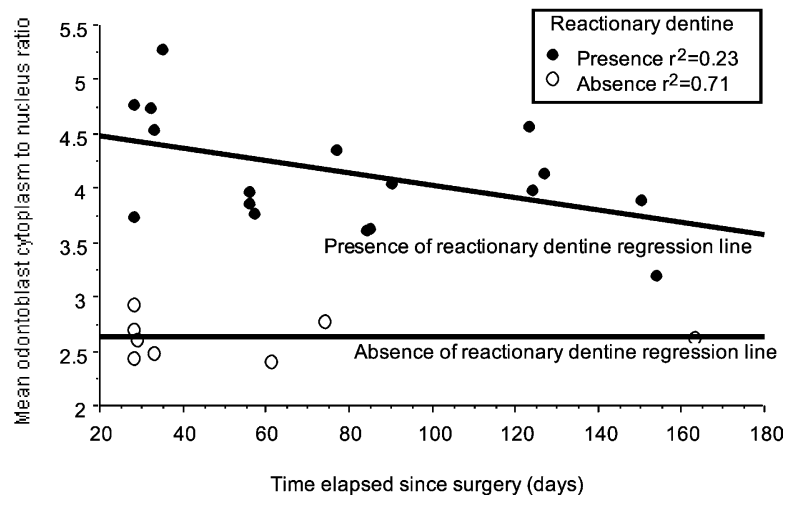

Figure 6 Time elapsed since surgery and odontoblast morphology. inflammatory activity (ANOVA $p=0.513$ ); Gender of patient (ANOVA $p=0.412$ ); Time elapsed since restoration (ANOVA $p=0.574$ ); and mandibular or maxillary premolar tooth position (ANOVA $p=0.700)$.

\section{Discussion}

The analysis of variance (LRANOVA) used in this study to examine odontoblast morphology, has been able to separate the effects of the cavity preparation, restoration and patient factor variables. The complexicity of these variables, has caused the analysis of clinical data to be problematic, hence aside from ethical and regulatory considerations, there has been a reliance on lesscomplex animal and laboratory experimentation to evaluate cavity restoration materials and restoration techniques. ${ }^{24,25}$ LRANOVA methods have shown the potential in this study to provide information about the morphological behaviour of human odontoblasts in response to restoration and patient factor variables. Furthermore, the technique of measuring the area of odontoblast cytoplasm, and dividing this, by the area occupied by the cell nucleus, proved to be a reliable and stable indicator of morphological changes occurring within each odontoblast cell. The cytoplasm to nucleus ratio was found to be in the range of $3-1$, this confirms the findings of previous studies. ${ }^{20,26,27}$

The quantitative relationship between dentine injury by cavity preparation, the secretion of reactionary dentine, and the cytoplasm to nucleus of the odontoblast cell, was demonstrated. Firstly, the cytoplasm of the odontoblast cells was increased as a proportion of the nucleus, secondly, the deposition of a reactionary dentine matrix was observed, and this was related to the cytoplasm to nucleus ratio. Thirdly, the odontoblasts that responded in this manner were located beneath cut dentinal tubules, and not at any pulpal locations independent of the cavity preparation. The increase in the cytoplasm to nucleus ratio in odontoblasts which had secreted a reactionary dentine matrix, suggested an inherent structural versatility of the odontoblast to increase its cytoplasmic organelles, and in doing so, to upregulate its capacity to synthesise and secrete reactionary dentine matrix. The increased cytoplasmic volume of the secretory odontoblast is characterised by an extensive rough-surface endoplasmic reticulum, a highly developed Golgi complex, and the presence of specific secretion granules. ${ }^{28}$ In the present study, up-regulation of secretory activity as 
measured by the area of reactionary dentine secreted by odontoblasts beneath cut dentinal tubules, has been found to be related to the cytoplasm to nucleus ratio. The fact that the size of the cytoplasm to nucleus ratio of odontoblasts, which had secreted reactionary dentine, was greater than odontoblasts that did not have this activity, suggests that the secretory capacity of the odontoblast was up-regulated in response to increases in its cytoplasmic area. Therefore, any increase in size of the cytoplasmic area is presumably as a direct result of the increased size of the dentine synthetic and secretory apparatus.

The cytoplasm to nucleus ratio of the odontoblasts beneath cut dentinal tubules had a tendency to decrease after reactionary dentine secretion was accomplished. The secretion of reactionary dentine matrix is rapid and highly regulated. ${ }^{8}$ Therefore, the secretory odontoblasts appeared to have a slightly reduced cytoplasm to nucleus ratio, between 26 and 163 following surgery, probably associated with the fact that reactionary dentine was probably no longer being secreted. In the absence of an active dentine injury stimulus, the secretory activity of these odontoblasts would probably decrease to their normal resting state. ${ }^{8}$ The reason for this cell behaviour is uncertain, but the ability to increase cellular synthetic and secretory apparatus, explains observations of the ability of the odontoblasts to respond to subsequent dentine injuries more rapidly and to secrete larger quantities of tertiary dentine. ${ }^{29,30}$ Reparative dentinogenesis on the other hand, which requires the replacement of damaged odontoblasts and the differentiation of a new generation of odontoblast-like cells, has been reported to have a lag time period, before its tertiary dentine secretory activity could be fully activated and completed. ${ }^{31}$ Because of the episodic nature of dental caries, it is likely that the tertiary dentine beneath a carious lesion may often comprise both reactionary and reparative dentines superimposed upon one another. $^{8}$

The morphological appearance of the odontoblast has been observed to vary widely throughout its life cycle. ${ }^{32-34}$ Despite this, the cytoplasm to nucleus ratio of odontoblasts in permanent premolar teeth did not appear to be correlated with the age of the patient between 9 and 17 years of age. Although maturation related physiologic and pathologic changes occur within the dental pulp tissue, ${ }^{35}$ in the present study, these maturation changes did not include observable alterations in the cytoplasm to nucleus ratio of the odontoblast cells. These observations may reflect the limited age of the tooth specimens examined, in which the odontoblasts might have been expected to be within the secretory phase of their life cycle. ${ }^{33}$

Nevertheless, pulpal maturation-related changes have been observed at the molecular level, ${ }^{36}$ and this could explain age-related changes in the dentine secretory activity of the odontoblasts. Age has been observed to have a role in the secretion of reactionary, physiologic sclerotic and reparative dentine. ${ }^{37}$ The dentinogenic response potential of teeth could be expected to reach a maturation plateaux and thereafter diminish into old age. ${ }^{38,39}$ But in this present study, the cytoplasm to nucleus ratio of the odontoblasts was not found to a good indicator of their age-related dentine secretory capacity. Similarly, there was little observable difference in the odontoblast cytoplasm to nucleus ratio between female and male patients, in response to a cavity cut into dentine. This was despite the fact that premolar eruption can be observed more than 1 year earlier in females, than in males. ${ }^{40}$ Other measured variables such as the pulpal inflammatory reaction, cavity restoration variables, choice of restoration material and the premolar tooth position, were also found not to be significant indicators of odontoblast morphology. This evidence would suggest that these variables have comparatively little effect. Above all else, the prime function of the odontoblast appeared to be to detect dentine injury and to repair this injury by secreting a reactionary or tertiary dentine matrix. The exact mechanism of dentine injury transduction to the odontoblast cells that causes their dentinogenic capacity to be up regulated is not clear. Some possibilities may include, firstly, the odontoblast process has a clearly defined role in the transport of secretory vesicles and their release into the extracellular space. ${ }^{41,42}$ However, the role of the process in communicating injury to the odontoblast cells is controversial, because some studies have suggested that the processes extends through only one-third of the whole length of the dentine tubules, ${ }^{43}$ whilst other studies have suggested that the process transverses the whole length of dentine and projects into tooth enamel. ${ }^{44}$

In reality, the length of the odontoblast process is probably variable, and so the operation of this dentin injury transduction system in isolation, would not adequately explain the ability of the odontoblasts to respond to peripheral dentin carious lesions. Despite the considerable controversy regarding the odontoblast process, and even the contents of the tubule lumen, ${ }^{45}$ the role of these structures in forming some part of the dentin injury transduction system cannot be discounted. Secondly, the tooth pulp is also densely innervated, ${ }^{46,47}$ and the intradentinal 
nerves may be able to mediate signals ${ }^{48}$ of dentine damage to the odontoblast cells. Thirdly, the molecular stimulus for the process of reactionary dentinogenesis, could be an effector molecule(s), perhaps a growth factor, which has been solubilised from the reservoir of endogeneous growth factors contained within the dentine matrix. ${ }^{49,50}$ Recently, the transforming growth factor (TGF) $\beta 1$ and $\beta 3$ isoforms have been demonstrated to up-regulate odontoblast dentinogenic activity at local sites of application. ${ }^{51}$ Indeed, the use of growth factors is expected to provide future clinicians with additional options for the treatment of substantially damaged or diseased vital teeth. ${ }^{52}$ The important relationships between cavity restoration variables and dental repair, and odontoblast numbers and dental repair, have recently been characterised. ${ }^{15,17}$ Nevertheless, much remains to be accomplished in order to better understand the mediators of dentinogenesis and the role played by the odontoblast. However, when this knowledge becomes available, it may permit improved treatment modalities for the injured pulp to be devised. ${ }^{53,54}$

\section{References}

1. Linde A, Goldberg M. Dentinogenesis. Critical Reviews in Oral Biology and Medicine 1993;4:679-728.

2. Baume LJ. The biology of pulp and dentin. Monographs in oral science. Switzerland; Karger: Basel; 1980. p. 159-82.

3. Stanley HR. Human pulp response to restorative dental procedures. Gainsville: Storter Printing Co; 1981.

4. Cox CF, White KC, Ramus DL, Farmer JB, Snuggs HM. Reparative dentin: factors affecting its deposition. Quintessence International 1992;23:257-70.

5. Smith AJ, Tobias RS, Cassidy N, Plant CG, Browne RM, BeguéKirn C, Ruch J-V, Lesot H. Odontoblast stimulation in ferrets by dentine matrix components. Archives in Oral Biology 1994;39:13-22.

6. Robertson A, Lundgren T, Andreasen JO, Dietz W, Hoyer I, Norén JG. Pulp calcifications in traumatised primary incisors: a morphological and inductive analysis study. European Journal of Oral Sciences 1997;105:196-206.

7. Lesot H, Smith AJ, Tziafas D, Bégue-Kirn C, Cassidy N, Ruch JV. Biologically active molecules and dental tissue repair: a comparative view of reactionary and reparative dentinogenesis with the induction of odontoblast differentiation in vitro. Cell and Materials 1994;4:199-218.

8. Smith AJ, Cassidy N, Perry H, Bégue-Kirn C, Ruch J-V, Lesot $\mathrm{H}$. Reactionary dentinogenesis. International Journal of Developmental Biology 1995;39:273-80.

9. Dachi SF, Stigers RW. Pulpal effects of water and air coolants used in high-speed cavity preparations. Journal of the American Dental Association 1968;76:95-8.

10. Tziafas D, Lambrianidis $T$, Beltes $P$. Inductive effect of native dentine on the dentinogenic potential of adult dog teeth. Journal of Endodontics 1993;19:116-22.

11. Chong BS, Pitt Ford TR, Kariyawasam P. Tissue response to potential root-end filling materials in infected root canals. International Endodontic Journal 1997;30:102-14.
12. Sigurdsson A, Stancill R, Madison S. Intracanal placement of $\mathrm{Ca}(\mathrm{OH}) 2$ : a comparison of techniques. Journal of Endodontics 1992;18:367-70.

13. Kahn FH, Rosenberg PA, Schertzer L, Kothals G, Hguyen PNT. An in vitro evaluation of sealer placement methods. International Endodontic Journal 1997;30:181-6.

14. Sazak S, Günday M, Alatli C. Effect of calcium hydroxide and combinations of ledermix and calcium hydroxide on inflamed pulp in dogs teeth. Journal of Endodontics 1996; 22:447-9.

15. Murray PE, About I, Lumley PJ, Smith G, Franquin J-C, Smith AJ. Postoperative pulpal and repair responses. Journal of the American Dental Association 2000;131:321-9.

16. Hilton TJ. Cavity sealers, liners, and bases: Current philosophies and indications for use. Operative Dentistry 1996;21:134-46.

17. Murray PE, About I, Lumley PJ, Smith G, Franquin J-C, Smith AJ. Human odontoblast cell numbers after dental injury. Journal of Dentistry 2000;28:277-85.

18. Baume LJ, Fiore-Donno G. Response of the human pulp to a new restorative material. Journal of the American Dental Association 1968;76:1016-22.

19. Benjamin N, Cleaton-Jones P, Leidal TI. Histometric evaluation of odontoblast responses to Nobetec and Super-Syntrex. Endodontics and Dental Traumatology 1985;1:180-4.

20. Bjørndal L, Darvann T, Bro-Neilsen M, Larsen R, Thylstrup A. An automated image analysis applied to the odontoblastpredentine region in undemineralised tooth sections in permanent third molars. Archives in Oral Biology 1997;42: $329-32$.

21. Scheffe H. A method for judging all contrasts in the analysis of variance. Biometrika 1953;40:87-104.

22. Dawson-Saunders B, Trapp RG, 2nd rev. ed. Basic and clinical biostatistics, vol. 125-143. Connecticut: Appleton and Lange; 1994. p. 54.

23. Mjor IA. Dentin and pulp. Reaction patterns in human teeth, Florida: CRC Press; 1983. p. 63-156.

24. Meryon SD. The model cavity method incorporating dentine. International Endodontic Journal 1988;21:79-84.

25. Fitzgerald M, Chiego Jr. DR, Heys DR. Autoradiographic analysis of odontoblast replacement following pulp exposure in primate teeth. Archives in Oral Biology 1990;35:707-15.

26. Bjørndal L, Darvan T. A light microscopic study of odontoblastic and non-odontoblastic cells involved in tertiary dentinogenesis in well-defined cavitated carious lesions. Caries Research 1999;33:50-60.

27. Sasaki T, Garant PR. Structure and organisation of odontoblasts. Anatomical Record 1996;245:235-49.

28. Stanley HR. Traumatic capacity of high-speed and ultrasonic dental instrumentation. Journal of the American Dental Association 1961;63:750-66.

29. Stanley HR, White CL, MCCray L. The rate of tertiary (reparative) dentin formation in the human tooth. Oral Surgery, Oral Medicine, Oral Pathology 1966;21:180-9.

30. Santini A, Ivanovic V. The quantitation of tertiary dentin formation in response to materials commonly placed in deep cavities in general practice in the UK. Primary Dental Care 1996;3:14-22.

31. Mjör IA, Dahl E, Cox CF. Healing of pulp exposures: an ultrastructural study. Journal of Oral Pathology and Medicine 1991;20:496-501.

32. Takuma S, Nagai N. Ultrastructure of rat odontoblasts in various stages of their development and maturation. Archives in Oral Biology 1971;16:993-1011.

33. Couve E. Ultrastructural changes during the lifecycle of human odontoblasts. Archives in Oral Biology 1986;31: 643-51. 
34. Romagnoli P, Mancini G, Galeotti F, Franchi E, Piereoni P. The crown odontoblasts of rat molars from primary dentinogenesis to complete eruption. Journal of Dental Research 1990;69:1857-62.

35. Morse DR. Age-related changes of the dental pulp complex and their relationship to systemic aging. Oral Surgery, Oral Medicine Oral Pathology 1991;72:721-45.

36. Moxham BJ, Webb PP, Benjamin M, Ralphs JR. Changes in the cytoskeleton of cells within the periodontal ligament and dental pulp in the first premolar tooth during aging. European Journal of Oral Sciences 1998;106(Suppl. 1): S376-S83.

37. Stanley HR, Pereira JC, Spiegel E, Broom C, Schultz M. The detection and prevalence of reactive and physiologic dentin, reparative dentin and dead tracts beneath various types of dental lesions according to tooth surface and age. Journal of Pathology 1983;12:257-89.

38. Smith AJ, Tobias RS, Plant GC, Browne RM, Lesot H, Ruch JV. In vivo morphogenic activity of dentine matrix protein. Journale de Biologie Buccale 1990;18:123-9.

39. Solheim T. Amount of secondary dentin as an indicator of age. Scandinavian Journal of Dental Research 1992;100:193-9.

40. Ten Cate AR. Oral histology: development, structure and function, 4th ed. St Louis: Mosby; 1994.

41. Holland GR. The odontoblast process; form and function. Journal of Dental Research 1985;64(Special issue):499-514.

42. Linde A, Lundgren T. From serum to the mineral phase. The role of the odontoblast in calcium transport and mineral formation. International Journal of Developmental Biology 1995;39:213-22.

43. Tidmarsh BG. Contents of human dentinal tubules. International Endodontic Journal 1981;14:191-6.

44. Ogita Y, Iwai-Liao Y, Higashi Y. A histological study of the organic elements in the human enamel focussing on the extent of the odontoblast process. Okajimas Folia Anatomica Japonica 1998;74:317-27.
45. Dai X, Ten Cate AR, Limeback H. The extent and distribution of intratubular collagen fibrils in human dentine. Archives in Oral Biology 1991;36:775-8.

46. Okamura K, Kobayashi I, Matsuo K, Taniguchi K, Ishibashi Y, Izumi T, Sakai H. Ultrastructure of the neuromuscular junction of vasomotor nerves in the microvasculature of the human dental pulp. Archives in Oral Biology 1994;39: 171-6.

47. Okamura K, Kobayashi I, Matsuo K, Taniguchi K, Ishibashi $Y$, Izumi T, Kitamura K, Sakai H. An immunohistochemical and ultrastructural study of vasomotor nerves in the microvasculature of human dental pulp. Archives in Oral Biology 1995; 40:47-53.

48. Norlin T, Hilliges $M$, Brodin L. Immunohistochemical demonstration of exocytosis-regulating proteins with rat molar dentinal tubules. Archives in Oral Biology 1999;44: 223-31.

49. Finkelman RD, Mohan S, Jennings JC, Taylor AK, Jepsen S, Baylink DJ. Quantitation of growth factors IGF-I, SGF/IGF-II and TGF-b in human dentine. Journal of Bone and Mineralised Research 1990;5:717-23.

50. Cassidy N, Fahey M, Prime SS, Smith AJ. Comparative analysis of transforming growth factor-beta isoforms 1-3 in human and rabbit dentine matrices. Archives in Oral Biology 1997;42:219-23.

51. Sloan AJ, Smith AJ. Stimulation of the dentin-pulp complex of rat incisor teeth by transforming growth factor-B isoforms 1-3 in vitro. Archives in Oral Biology 1999;44:149-56.

52. Rutherford B, Fitzgerald M. A new biological approach to vital pulp therapy. Critical Reviews in Oral Biology and Medicine 1995;6:218-29.

53. Tziafas D. Basic mechanisms of cytodifferentiation and dentinogenesis during dental pulp repair. International Journal of Developmental Biology 1995;39:281-90.

54. Piattelli A, Trisi P. Pulp obliteration: a histological study. Journal of Endodontics 1993;19:252-4. 